\title{
THE ROLE OF FORENSIC DENTIST FOLLOWING MASS DISASTER
}

\author{
B. Kolude'; B.F. Adeyemi' ${ }^{1}$ J.O. Taiwo ${ }^{2}$; O.F. Sigbeku'; U.O. Eze ${ }^{3}$
}

1. Department of Oral Pathology, UCH, Ibadan

2. Department of Periodontology \& Community Dentistry, UCH, Ibadan.

3. Department of Pathology, UCH, Ibadan.

Correspondence:

Dr. B. Kolude

Department of Oral Pathology,

Faculty of Dentistry,

College of Medicine,

University College Hospital campus,

Ibadan, Nigeria.

delekolude2003@yahoo.co.uk

\begin{abstract}
This review article focuses on mass disaster situations that may arise from natural or manmade circumstances and the significant role of forensic dental personnel in human identification following such occurrences. The various forensic dental modalities of identification that include matching techniques, postmortem profiling, genetic fingerprinting, dental fossil assessment and dental biometrics with digital subtraction were considered.

The varying extent of use of forensic dental techniques and the resulting positive impact on human identification were considered. The importance of preparation by way of special training for forensic dental personnel, mock disaster rehearsal, and use of modern day technology was stressed. The need for international standardization of identification through the use of Interpol Disaster Victim Identification (DVI) forms was further emphasized.

Recommendations for improved human identification in Nigerian situation include reform of the National Emergency Management Association (NEMA), incorporation of dental care in primary health care to facilitate proper ante mortem database of the populace and commencement of identification at site of disaster.
\end{abstract}

\section{INTRODUCTION}

Mass disaster may be caused by natural events such as severe flooding, earthquake or volcanic eruption. It may also be caused by human activities such as mishaps involving mass transport by land, sea or air; other causes include war, boundary disputes, ethnic or religious conflicts and as in the Nigerian situation, petroleum pipe line explosion ${ }^{1,2} \& 3$.

Following mass disaster, identification of individual victims by dental means is one of the most reliable methods (figure 1). In severe burn situations and/or following severe disintegration, visual recognition of facial features and fingerprints is often impossible due to extensive soft tissue destruction; this situation often necessitates the use of hard (calcified) tissue such as human dentition and jaw bones for human identification. Persons who have been diseased for some time prior to discovery and those found in water also present unpleasant and difficult visual identification ${ }^{4}$. Dental identification plays a key role in natural and manmade disaster especially in mass casualties associated with aviation disasters, a situation that has also been highly recurrent in Nigeria in the last two decades.
Victim's identity may be based on uniqueness of concordant ante mortem and post mortem dental features which often lead to positive recognition or provide convincing proof to rule out a particular identity. Dental identification is based on pathological conditions such as: disturbance of tooth eruption, malocclusions and/or previous dental treatments. Changes brought about by age, pathological conditions, and developmental disturbances or by intervention of the dental surgeon result in the mouth being unique to the individual ${ }^{5}$.

The objective of this review is to intimate medical and dental practitioners of the crucial role of dentist in victim's identification and to further motivate relevant trainee dental specialist to consider the scope and career uptake in this unique disciple. 


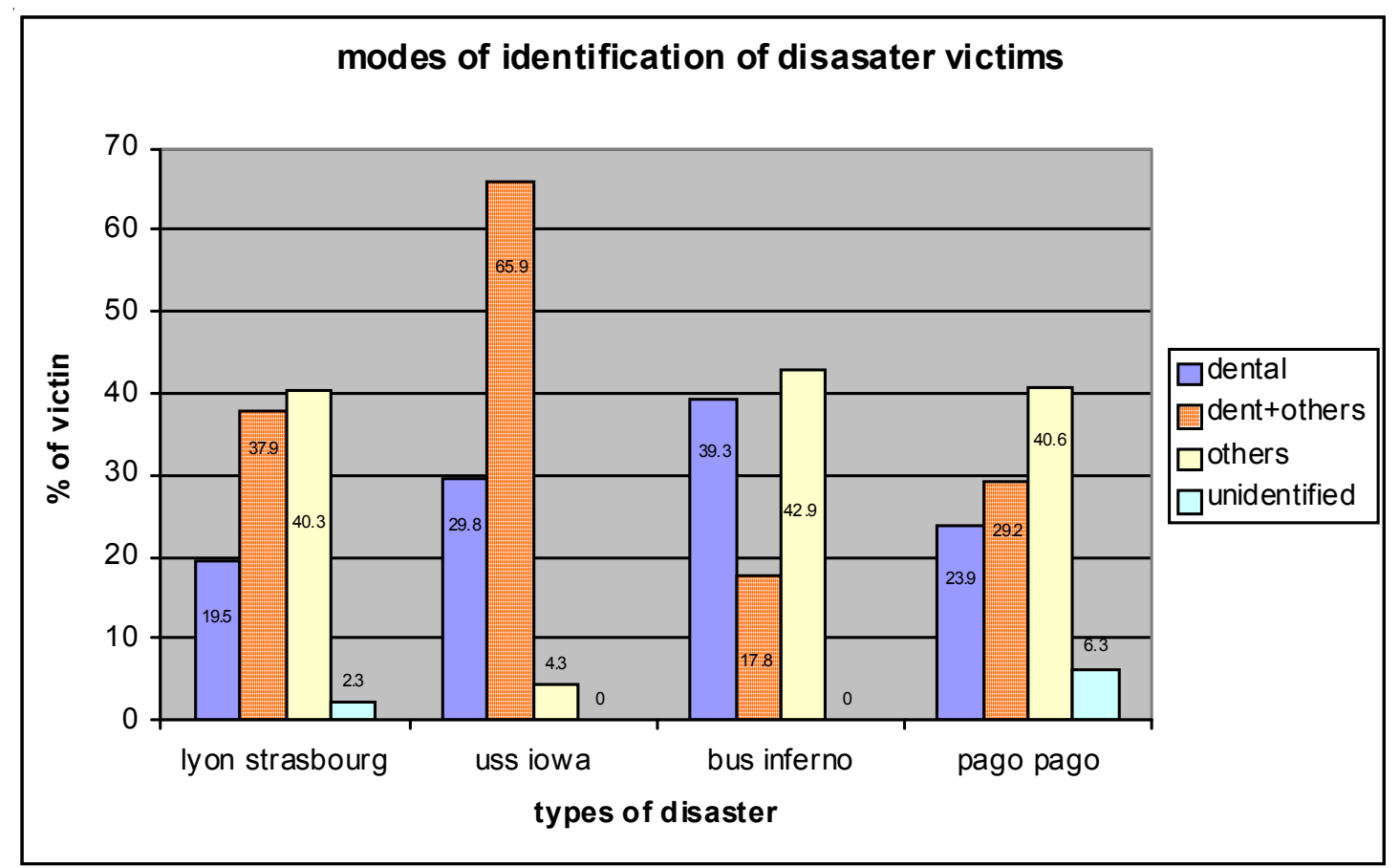

Figure 1: Disaster types and modes of identification of victims

\section{Roles of the forensic dentist}

The roles of the forensic dentist include criminal investigation using bite marks, dental cast and saliva analysis; dentists also assist in resolving parental contentions with DNA analysis through a process called genetic fingerprinting. The most common role of a forensic dentist is the identification of deceased persons either for crime resolution or for social, matrimonial, or financial reasons ${ }^{6}$.

The first and the most frequent investigation is the comparative examination used to establish to a high degree of certainty that the remains of deceased and the person represented by ante mortem dental records are the same individual. In Nigeria, comprehensive fingerprint database and complete ante mortem dental records are most often lacking, so making comparative dental identification almost a mirage. The second investigation is for cases without previous ante mortem records and where no clues to positive identity exist. Under this circumstance, postmortem dental profile is completed by the forensic dentist suggesting characteristics of the individual and so narrowing search of the ante mortem materials ${ }^{7}$. With the advent of advanced analytical computer software packages, dental biometrics - the matching of ante mortem and postmortem dental radiographs for human identification has come into prominence in instances of unavailable fingerprint or facial features.

Comparative Dental Identification: The central issue here is that postmortem dental remains can be compared with ante mortem dental records including written notes,
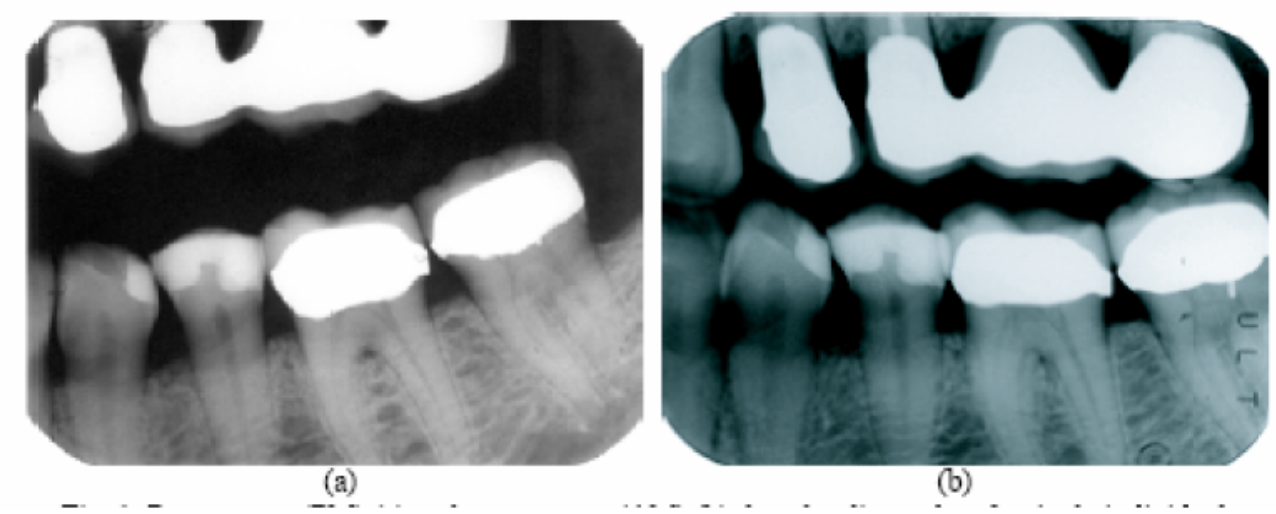

(b)

Figure 2: Postmortem PM (a) and ante mortem AM (b) dental radiograph with many restorations (dense radio opacity) 
study casts and radiographs to confirm identity. Individuals with numerous and complex restorations are often easier to identify than those with little or no restorative treatment (figure 2). The teeth in as much as representing the suitable store of these unique identifying features also survive most post-mortem events that damage or disrupt most body tissues ${ }^{8,9}$. Forensic dentists produce post-mortem records based on careful charting and written description of dental structures and radiographs of the deceased.

Following a methodical and systematic comparison of ante-mortem and post-mortem records of each tooth and surrounding structures such as bony prominences and congenital defects followed by dental restorations, similarities and discrepancies are noted ${ }^{10}$. There are two types of discrepancies, those that can be explained and those that cannot. Explainable discrepancies are those related to time lapse between ante mortem and post-mortem records such as extracted teeth or extended or enlarged restorations while unexplainable discrepancies cannot be resolved by time lapse between ante-mortem and post-mortem records for example a post-mortem tooth which was absent on ante-mortem record.

The American Board of Forensic Odontologists ${ }^{11}$ recommends only four conclusions when reporting dental identification:

(1) Positive identification: the ante-mortem and postmortem records match in details with no unexplainable discrepancies.

(2) Possible identification: - ante-mortem and postmortem data have consistent features but due to poor quality, identity cannot be positively established.

(3) Insufficient Evidence: - available information is insufficient to form basis for a conclusion.

(4) Exclusion: - the ante-mortem and post-mortem data are clearly inconsistent.

There is no minimum number of concordant points for positive identification - a single tooth containing unique features can be used for identification while a full mouth radiograph may not reveal sufficient detail for positive conclusion

The Scandinavian Forensic oral pathology assessment includes the following post-mortem and ante-mortem details ${ }^{12}$ :-

Post-mortem data:-

(A) Site of accident:- (car, boat, home, flight, vacation cabin, etc)

(B) Severity of injury:Grade 0: No injury
Grade 1: Injury to anterior teeth (in one or both jaws)

Grade 2: Injury to anterior and posterior teeth unilaterally (in one or both jaws)

Grade 3: Injury to anterior and posterior teeth bilaterally (in one or both jaws)

Grade 4: Fragment of both jaws including teeth and or roots.

Grade 5: No dental remains.

Dental registration:-

- Intact/sound, filled (restorative material specified), surfaces, root filling and missing teeth

- Prosthesis:- fixed (crowns and bridges) and removable prosthesis

- Developmental disorders: - impactions hypo and hyperdontia, ectopic, transposition or retained teeth.

- Malocclusions: - mesial molar occlusion, frontal open and deep bite $>5 \mathrm{~mm}$. crossbite scissorsbite, midline displacement, crowding and spacing.

Evidence of pathological changes :- jaw fractures, tumousrs, major infections (sinusitis, osteomyelitis)

Ante mortem data:-

Quality of ante-mortem dental records was categorized as follows:-

Grade 0:- No information.

Grade 1:- Information without written records.

Grade 2:- Written records only.

Grade 3:- Record combined with unsystematic radiograph.

Grade 4:- Record combined with bitewings.

Grade 5:- Record combined with full mouth survey or an orthopanthomograph

Post-mortem dental profiling: Post-mortem dental profiling is the process by which forensic dentists limit the likely population to which a deceased belongs in the absence of ante-mortem dental records. Post-mortem dental profile will provide information on age of deceased ${ }^{13}$, ancestral background ${ }^{6,14}$, sex, and socioeconomic status $^{15}$.

Age of children (including fetuses and neonates) can be determined by analysis of tooth development and subsequent comparison with developmental chart; accuracy is \pm 1.5 years $^{16}$.

Periodontal disease progression, excessive wear and multiple restorations, extractions, bone pathology and complex restorative work may indicate an older individual; accuracy of these highly variable markers is \pm 10 to 12 years. Some forensic dentists claim accuracy of \pm 4 years using aspartic acid racemization. (Scanning Electron Microscope/Energy Dispersive X-ray Spectroscopy) SEM EDXS is also used to examine 
restorative materials including resin in relation to age determination in cases where dental status of victims cannot be determined due to damaged dentition.

SEM/EDXS can analyze different resins and couple each spectrum to a specific brand name because the inorganic composition of resin is rarely altered; data obtained provides information about the time frame that the product was in market thus giving an idea of the remains chronolog $\mathrm{y}^{17}$.

Sex and ancestry is assessed from skull shape and form. A forensic dentist can determine race within three major groups (Caucasoid, mongoloid and negroid) from skull appearance and tooth features such as cusp of Carrabelle, shovel shaped incisors and multi cusped premolars. Microscopic examination of teeth can further confirm sex by presence or absence of $y$ chromatin and DNA analysis can also reveal sex ${ }^{16}$.
Other information on socio-economic status includes occupation, dietary habits, and habitual behaviors, dental or systemic diseases. Presence of erosion can suggest alcohol or substance abuse, an eating disorder or even hiatus hernia while stains can indicate smoking, tetracycline use or betel nut chewing. Unusual dentition wear results from pipes stems, cigarette holders, hairpins, carpet tacks or previous orthodontic treatment. The quality, quantity, presence or absence of dental treatment may give an indication of socioeconomic status or country of residence. If postmortem dental profile is inadequate for identity, forensic artists may construct individual appearance during life using dental profile as an aid for facial reproduction ${ }^{6}$.

Other methods of dental identification:-

Other methods of dental identification include dental biometrics $^{18}$ and genetic fingerprinting ${ }^{19}$.

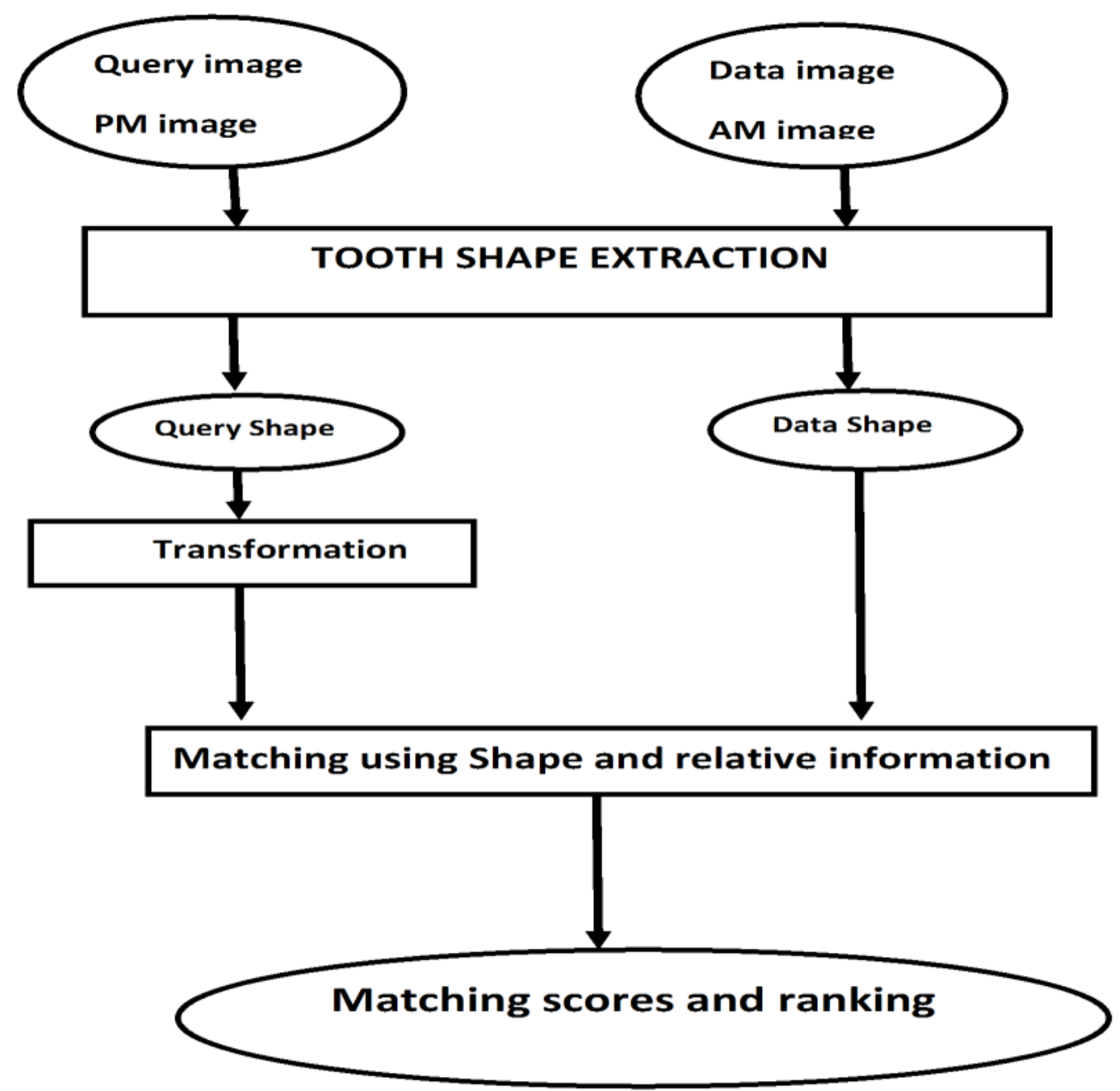

Fig. 3: The logical modules of the dental biometric system 
Dental biometrics automatically analyzes dental radiographs to identify the deceased individuals for whom other means of identification (e.g. finger prints, face, etc) are not available. Dental radiographs provide valid accurate and reliable information about the identity of an individual. The method used in dental biometrics is the matching of unlabelled post-mortem radiographs against the labeled ante-mortem radiographs. If the set of teeth in a post-mortem radiograph sufficiently matches the teeth in an antemortem radiograph, the identity of the deceased in the post-mortem radiograph is obtained.

There are two stages for dental biometrics are feature extraction, and matching.

During feature extraction, the tooth contours and the dental work shapes are extracted while at the stage of matching, the identification is obtained in three steps; matching at the tooth level, matching at contextual level and matching at subject level. Extraction of tooth contour involves radiographic segmentation and gum line detection. The methods include;

(a) Pixel classification.

(b) Adaptive thresholding.

(c) Active contour modeling.

Beside tooth contours, dental work shape is dental information that is useful for identification as shown in figure 2 .

Matching has three steps at the first step; the tooth contour and dental work shapes of the neighboring teeth are matched. The second step is matching at the contextual level; this step reduces the searching scope and enhances the matching accuracy by binding neighboring teeth into groups. The final step is matching at subject level, every unidentified subject has several post-mortem images and every ante-mortem image in the database belongs to a subject. The matching at the subject level is to obtain the identity of a group of post-mortem images that marches the supposed ante-mortem image of the subject ${ }^{20}$.

$D N A$ in dental identification: - dental tissue is resistant to incineration, immersion, trauma, mutilation and decomposition so it represents an excellent reservoir of DNA materials. When conventional dental identification methods fail, biological material such as DNA may provide necessary link to establish identity. Genetic fingerprinting, DNA testing, DNA typing or DNA profiling is a technique used to distinguish between individuals of the same species using only samples of their DNA. It was invented by Sir Alec Jeffrey's at the University of Leicester in 1985. Genetic fingerprinting is used in forensic science to match suspect's sample to samples of blood, hair, saliva or semen, this can lead to conviction or exoneration of suspect, it is also useful for paternity testing and for identification of dead bodies ${ }^{19}$.

The present day DNA fingerprinting is based on polymerase chain reaction (PCR) that undergoes genetic amplification of short tandem repeats (STR are selective, highly polymorphic regions of DNA). This allows for comparison of DNA from teeth, jaws and other parts of unidentified individuals with a known ante mortem sample from clothing, stored blood, hair brush, cervical smear or biopsy specimen.

Apart from genomic DNA, cells also contain mitochondrial DNA (mtDNA) with the advantage of high copy number due to high number of mitochondria present in most cells such that in instances of high degradation where genomic DNA is inadequate, mtDNA may be present in sufficient quantity. mtDNA is maternally inherited so barring mutation, siblings and maternal relative share similar mtDNA. This is very useful where ante mortem samples are lacking for comparison ${ }^{21}$.

In a classical case, the DNA of Joseph Mengele the chief physician during the systematic extermination of the Jews at the holocaust was extracted from one of his bone remains and compared with DNA from his son and mother, and in April 1992, report indicated a clear genetic resemblance thus closing the search for the late sadist.

In highly destructive disasters in the magnitude of the 11th of September 2001 air disaster, where most of the nonmetallic contents including human bodies were converted to homogenous dust DNA becomes the most useful tool for human identification.

\begin{tabular}{lll}
\hline $\begin{array}{l}\text { nearly } \\
\text { fewer than } \\
\text { fewer than } \\
\text { over }\end{array}$ & $\begin{array}{l}2800 \\
1,600\end{array}$ & $\begin{array}{l}\text { victims } \\
\text { whole bodies found } \\
\text { victims identified } \\
\text { victims remain } \\
\text { unidentified }\end{array}$ \\
$\begin{array}{l}\text { nearly } \\
\text { over }\end{array}$ & $\begin{array}{l}20,000 \\
\text { pieces of bodies found } \\
\text { pieces small enough to } \\
\text { fit in test -tubes } \\
\text { pieces m atched to single } \\
\text { person } \\
\text { unidentified pieces } \\
\text { frozenforfuture analysis }\end{array}$ \\
\hline
\end{tabular}

Table 1: The role of DNA analysis in the forensic analysis of 911 disasters

\section{DISCUSSION}

Planning is crucial for successful identification of victims in mass disasters and a special identification team should be responsible for the work. Identification 
(ID) commissions in many countries may consist only of police officers with forensic pathologist and forensic dentist being called upon only when deemed necessary and sometimes these professionals are not specially trained and have little influence in the final identification $^{22,23}$.

The organization of a record system for the dental status of individuals, that will be part of the health system of every country, will contribute to the minimization of the expenses of the policing agencies and to more rapid and accurate identification process ${ }^{24}$. In the United States of America, the decision on identity is the responsibility of coroner or medical examiner, in Britain identification is often left to private funeral companies that often employ specialists as staff members $^{25}$. In Nigeria a country that has witnessed several episodes of fire disaster in the last two decades involving both aviation and petroleum industries by way of plane crashes and pipeline explosions, the response to mass disaster is handled by the National Emergency Management Agency (NEMA) ${ }^{26}$

The Scandinavian model ${ }^{12}$ with equal responsibility to different professional sections may be ideal for correct identification in mass disaster where specially trained pathologists and forensic dentists are formal members of the Identification Commission is hereby advocated for adoption in Nigeria, as special training will improve medical assistance at scene of accident which is often an unfamiliar terrain to the medical team compared to the morgue.

For the most effective identification following mass disaster, identification work must start at the scene of the accident; special equipments including radiographic machines should be available at the scene of accident as the most careful handling of charred bodies may cause the jaws to crumble ${ }^{27}$. The INTERPOL DVI (Disaster Victim Identification) form was designed by experts from various countries and recommended by INTERPOL for international use as it allows for uniformity and standardization of records following mass disaster. The yellow form is for transcribing information from ante-mortem records while the pink form is for post-mortem record. To minimize errors, transcription of ante-mortem dental information should be done independently by two forensic dentists so as to double check for discrepancy.

The success rate of dental identification will vary considerably depending on the nature of the accident, the degree of dental injury, the incidence of dental treatment and the availability of adequate dental records which is a function of the nationality and country of residence of victims?
The verification of identity of fire victims established by dental means has previously been reported to range between 34 and $89 \% \%^{28,29,30,31 \& 32}$. In western countries, when dealing with fire victims, much weight is put on dental evidence and a strict criterion for "established" identification is often employed ${ }^{30,31 \& 32}$, in Scandinavian countries with properly structured health care service where only a minority of citizens have no ante mortem dental records, the dental identification following fire disasters is at the upper limit with only a minority falling under non conclusive dental identification (range is 8 to $26 \%$ in a review of several fire disasters ${ }^{10}$.

\section{Conclusion and Recommendations}

Dental examination is a powerful tool in the identification of deceased. The key to successful mass disaster identification is preparedness. The National Emergency Management Agency should have forensic dentists incorporated in the emergency response team; formally constituted Identification Commission with two specially trained forensic dentists in each unit of identification in keeping with international standard is desirable. Professionals in the team should be exposed to state of the art equipments such as computer based ID programmer and laboratory analyzer for speedy visual and electronic comparison by regular training at appropriate centre worldwide and mock disaster scenarios for emergency preparation should be a regular feature. Identification work should start at the scene of accident so appropriate transportation with well equipped vehicles by road and air is necessary for this quick response team.

Routine dental check up with appropriate radiography should come under primary care service in the National Health Insurance Scheme, this will afford reasonable generation of broad based national ante mortem dental records for comparison at mass disaster instances, This routine check up by legislation should be included in the admission criteria into primary, secondary and tertiary institutions and also serve as a prerequisite for employment nationwide.

\section{REFERENCES}

1. Fadeyibi IO, Omosebi DT, Jewo PI, Ademiluyi SA. Mass burns disaster in Abule-egba, Lagos, Nigeria from a petroleum pipeline explosion fire Annals of Burns and Fire Disasters - vol. XXII n. 2 - June 2009.

2. Ehikhamenor EE, Ojo MA. Comparative Analysis of Traumatic Deaths in Nigeria. May June 2005 http://pdm.medicine.wisc.edu Prehospital and Disaster Medicine.

3. JainR, RajooKM. Mass disaster management: Forensic aspect. Journal Ind Acad Forens Med: 2009; 31 (2): 234-392. 
4. Valenzuela A, Martin-de las Heras S, Marques T, Exposito N. Bohoyo JM. The application of dental methods of identification to human burn victims in a mass disaster. Int. J Legal Med 2000; 113: 236-239.

5. Valenzuela A, Marques T, Exposito N, MartinDe Lashers Garcia G. Comparative study of efficiency of dental methods for the identification of burn victims in two bus accidents in Spain. Am J Forensic Med Pathol. 2002; 4: 390-3.

6. Pretty IA, Sweet D. A look at forensic dentistry - Part 1: The role of teeth in the determination of human identity. Br. Dent J. 2001; 109(7): 359366.

7. Stavrianos C, Stavrianou I, Dietrich E. Kafas P: Methods for human identification in Forensic Dentistry: A Review. The Internet J Forensic Sci. 2009; 4 (12): 413-421.

8. Komar D, Lathrop S. Frequencies of morphological characteristics in two contemporary forensic collections: implications for identification. J Forensic Sci. 2006; 51(5): 974-978.

9. Sweet D, Dizinno JA. Personal identification through dental evidence of tooth fragments to DNA. J Calif Dent Assoc. 1996; 24(5):35-42.

10. Campobasso CP, Dell'erba AS, Belvisom, DI Vella G. Craniofacial identification by comparison of antemortem and post-mortem radiographs: two case reports dealing with burnt bodies. Am J Forensic Med Pathol. 2007; 28(2):182-186.

11. Body identification guidelines. American Board of Forensic Odontology (ABFO). J Am Dent Assoc. 1994; 125 (9): 1244-1246.

12. Solheim T, Lorentsen M, Sundnes PK, Bang G, and Bremnes L The "Scandinavian Star" ferry disaster 1990 - a challenge to forensic odontology Int J Leg Med 1992; 104 : 339-345.

13. Mincer $\mathbf{H H}$, Harris EF, Berryman HE. The A.B.F.O. study of third molar development and its use as an estimator of chronological age. J Forensic Sci. 1993; 38(2): 379-390.

14. Guo L, Sun DL, Ren L, Shen J, Pan KF, Shen J et al. A comparative morphologic study of Carabelli cusp between Chinese and Japanese students. Shanghai Kou Qiang Yi Xue. 1995; 4(2): 66-67.

15. Slavkin HC. Sex, enamel and forensic dentistry: a search for identity. J Am Dent Assoc. 1997; 128(7): 1021-1025.

16. Adachi H. Studies on sex determination using human dental pulp. II. Sex determination of teeth left in a room. Nihon Hoigaku Zasshi. 1989; 43(1): 27-39.
17. Bush MA, Miller RG, Norrlander AL, Bush PJ. Analytical Survey of Restorative Resins by SEM/ EDS and XRF: Databases for Forensic Purposes. J Forensic Sci. 2008; 53(2): 419-425.

18. Hong C, Anil KJ. Dental Biometrics: Alignment and Matching of Dental Radiographs: IEEE transactions on pattern analysis and machine intelligence 2005; 27 (8): 1319-1326.

19. Signer EN, Dubrova YE, Jeffreys AJ., Wilde C, Finch LM. DNA fingerprinting Nature 1998; 394: 329-330.

20. Jain AK and Chen A, "Matching of Dental XRay Images for Human Identification," Forensic radiol. 2004; 37 (7): 1519-1532.

21. Sweet D, Hildebrand D. Recovery of DNA from human teeth by cryogenic grinding. J Forensic Sci 1998; 43: 1199-1102.

22. Solheim T, van den Bos A. International disaster identification report - investigative and dental aspects. Am J Forensic Med Pathol 1982; 3: 6367.

23. Hooft PJ, Noji EK, van de Voorde HP. Fatality management in mass casualty incidents. Forensic Sci Int 1989; 40: 3-14.

24. Blau S, Hill A, Briggs CA, Cordner SM. Missing persons-missing data: the need to collect antemortem dental records of missing persons. J Forensic Sci 2006; 51(2): 286-289.

25. Clark DH. Dental identification problems in the Abu Dhabi air accident. Am J Forensic Med Pathol 1986; 7: 317-321.

26. Funayama M, Kanetake J, Ohara H, Nakayama Y, Aoki Y. Dental identification using digital images via computer network. Am J Forensic Med Pathol. 2000; 21(2): 178-183.

27. Chandra Shekar BR, Reddy C. Role of dentist in person identification. Indian J Dent Res 2009; 20: 356-360

28. Chapenoire S, Schuliar Y, Corvisier JM. Rapid, efficient dental identification of $92 \%$ of 13 train passengers carbonized during a collision with a petrol tanker. Am J Forensic Med Pathol 1998; 19: 352-355.

29. Clark DH. An analysis of the value of forensic odontology in ten mass disasters. Int Dent J 1994; 44: 241-250. .

30. Morlang WM. Dentistry2s vital role in disaster preparedness. J Calif Dent Assoc 1996; 24: 63-6.

31. Soomer $\mathbf{H}$, Ranta $H$, Pentila A. Identification of victims from the M/S Esthonia. Int J Leg Med. 2001; 114: 259-262 